\author{
Mediterranean BioMedical Journals \\ Integrative Journal of Medical Sciences \\ 2020, Volume 7, ID 222 \\ DOI: 10.15342/ijms.7.222
}

RESEARCH ARTICLE

\title{
Patterns of Explicit and Subtle Racism and Self- reported Color in Health Services
}

\author{
Cristina Gomes \\ Facultad Latinoamericana de Ciencias Sociales, FLACSO-México \\ Carretera al Ajusco 377, Tlalpan CP 14200, Mexico City, Mexico
}

\begin{abstract}
In this research, racism is defined as a multidimensional configuration of beliefs, emotions and behavioral guidelines to discriminate against black individuals.

A representative survey was applied to 634 workers of public and private health services in the municipality of Camaçari, State of Bahia, Brazil, to explore technical knowledge, perceptions, attitudes and behaviors regarding to inequalities and racism. Principal Component Analysis was used to reduce and classify 40 sentences into standardized profiles of sets of components represent the sharing of social attitudes, beliefs on racism among health personnel.

Results show that racism is expressed mainly through subtle expressions. Most of the health personnel disagree to asking the patients' color. Health personnel who self-declare as white would accept explicit expressions of racism: that black patients would be more violent by nature; those who self-declared as brown would accept that humiliating jokes against black patients are normal expressions of Brazilian culture. These perceptions are based more on social prejudices, oriented by ideology, with contradictions and ambiguities in racism perceptions and with the values in modern society, such as universalism and equality. Racism in health services works as a barrier to complete and improve data on color-race inequalities in health and to implement affirmative policies.
\end{abstract}

KEYWORDS: Racism, Health Services, Health Personnel, Perceptions, Out-Group, Values, Prejudice, Ideology.

Correspondence: Cristina Gomes. Magisterio Nacional 196 casa 2, Tlalpan Centro, Tlalpan, CP 14000, Mexico City, Mexico. Cell phone: 5255 61464362. Email : cristinagomesmx@gmail.com

Copyright $(92020$ Gomes C. This is an open access article distributed under the Creative Commons Attribution 4.0 International, which permits unrestricted use, distribution, and reproduction in any medium, provided the original work is properly cited.

\section{INTRODUCTION}

Racism in Brazil is structural, reflecting more than four centuries of slavery, and is reproduced by institutions and civil society in daily and family life.

After 13 years promoting the inclusion of black population in public services, this research evaluates the implementation of the National Policy for Integral Health of Black Population in health services in the municipality of Camaçari, State of Bahia, Brazil.

It is estimated that more than six million Africans were trafficked and enslaved in Brazil between the fifteenth and the nineteenth century; and, even after their release, following the end of empire and the proclamation of the republic in the late nineteenth century, newly freed blacks remained marginalized and were not included in the labor market, neither having the rights to vote, to receive education, to access health services, nor own land or property [1-3].
After the abolition of slavery, black people migrated and occupied marginal areas of the urban areas, like Salvador and Rio de Janeiro, and survived by seeking any kind of work in informal commerce and services, as they were replaced by millions of European and Asian immigrants in the new republican economy. European immigrants received support from the State to travel and received land in Brazil to promote their development as small and middle agricultural producers in rural areas, or as formal workers in the emerging banks, commerce and services in urban areas. European immigration was planned and organized as a government project to whiten the Brazilian population [4-8]. Africans and their descendants have never received any reparation - they were abandoned by the State - and racism continued to be massively reproduced and legitimated in all the spaces and 
institutions in behavior, speeches, vocabulary, identities, attitudes, values and daily practices.

Since the arrival of Africans and until the beginning of the 21st Century, the Brazilian population has been predominantly black, slave or descendant of enslaved, illiterate and, until the beginning of the 20th Century, described in the newspapers and Brazilian academics as bestialized (made beasts) - a reason for national shame [9].

In 1888, Brazil was the last country in Latin America and the penultimate in the world to abolish slavery.

Structural racism has become an intrinsic part of the formation, development, and identity of Brazilian society, and has been reproduced through a false myth of racial democracy and the ideal of whitening the society. A sui generis racism, masked and widespread, combined with several types of legitimated aggressiveness, persists in all structures of power at national level and state level, in municipal institutions, and a micro social level, both individual and familial $[6-8,10,11]$.

As a result, blacks in Brazil have the worst rates of morbidity, mortality, and illiteracy, and have the lowest educational levels and highest poverty rates in the population [7]. There are incidents of racism witnessed on a daily basis in the media, social networks, public spaces and institutions and even among members of the same family, but prejudices and discriminatory attitudes are denied and hidden, masked in a belief that in Brazil there is a peaceful miscegenation process and an alleged racial democracy [2, 5-8].

According to several authors, racism in modern Brazil is reproduced according to two basic ideas; a) the myth of racial democracy, since Brazilians believed over centuries that miscegenation was a harmonic, peaceful and even a glamorous process in the national history, and b) population whitening, as an ideal promoted by government policies to attract European migration after the end of slavery and, as a high value, incorporated in intergendered relationships and practices to this day [2,58].

Brazilian racial culture would work under a mask of racial democracy.

According to $[2,7,10]$ prejudice plays its daily aggression against black people alternating silences, whispers, speeches and shouts. The first two forms are the most used, because they allow racism to hide while acting to keep the facade of people as morally intact, mentally healthy (the good ones), which would have authority to discriminate and have power over the other, since blacks are considered to be in an inferior social position (the bad ones).

By extending these local approaches, this article adopts the concept that racism should be analyzed according to its institutional and behavioral expressions, as well as a construction derived from a large historical process that legitimated slavery, attempted to whiten the race by miscegenation, and promoted European migration segregating the black population after abolition - and, finally, inculcating the eugenics principles of natural white superiority and black inferiority. The eugenics pseudo-science, guided exclusively by ideology, divided humanity according to phenotype labels, supposedly related to cultural and intellectual capacity and the concept of human races, attributing hierarchical definitions to the categorization of individuals who were white, black, brown, yellow/Asian, indigenous, and so on [12 ].

As a result of centuries of slavery, abandonment, and other forms of violent submission and exploration, Brazilian society was educated to be racist for generations. And racism should currently be considered structural, as blacks are often perceived as a problematic, conflictive and negative category. This negative perception is based on persistent values and ideology that orient emotional, cognitive and behavioral reactions, and deeply affect identity, the sense of belonging to an ingroup, the representation of the 'other' ('otherness'), and intergroup perceptions, competitions and relationships $[13,14,15]$.

As racism was criminalized in this century and democratic governments implemented a set of affirmative policies to promote racial equality [16], the explicit and aggressive racist expressions and emotions legitimated in the past centuries were replaced by a more subtle racism - non-derogatory speech, beliefs and behavior that promote silence, invisibility, and even condescendence as reformed remnants of the previous aggressions. This subtle racism combines the recognition of and tolerance of race inequalities, as well ambiguities and contradictory beliefs and attitudes, based on real and imagined competitions, feelings of deprivation, frustration and aggression in intergroup identities, perceptions, and relationships [13- 15 ]. These changes imply great challenges to identify the different forms of racism analyzed in current research.

These are the reasons behind the starting point of this research being in Brazil - to measure, with quantitative exploratory methods, how much and in what directions the racist narratives extracted from qualitative research can be related to the new expressions of explicit and subtle racism, and what the ambiguities and contradictions orienting identities, in-group and outgroup belonging, and inter-group perceptions, attitudes and practices.

In Brazil, the negro population is a sum of people who declare themselves as black or brown. In 2013, these groups represented $52.9 \%$ of the population, around one hundred million people. In the public health system (SUS), 70\% of the users are self-declared as black (black and brown). Brazil is the country with the second largest number of black people in the world - the first is Nigeria. Bahia is the State with the highest proportion of black inhabitants, as is the Metropolitan Region of Salvador, the capital of the State, where Camacari is included [8].

Censuses and surveys in Brazil ask for color or race according to the method of induced self-declaration. Interviewed people choose between five categories: black, white, brown, Asiatic, or indigenous. Since the 90s different questionnaires have also included spontaneous answers to an opened question: How do you define your color or race? [17] compared both questions to explore the reliability of the five categories officially adopted for 
one century. The results are conclusive for different surveys: there are no contradictions - on the contrary, in almost all cases, most of the answers to the open question reconcile with the five official categories, and these categories are well accepted and known by the population [17].

[17 ] has also found that, contrary to the total population, the majority of federal agency civil servants didn't selfdeclare their color-race in questionnaires of government records. Only $40 \%$ of the 584,000 active employees completed the question of color or race in their record of personal data in 2003 and, in some institutions, only $3 \%$ of the public employees responded to this question [17, $18]$.

In Brazil the black population (both black and brown) has the highest rates of illiteracy and poverty, of morbidity and mortality caused by diabetes, hypertension and violence, maternal and infant mortality as well as the highest prevalence of sickle cell disease [8, 19-21].

\section{MATERIALS AND METHODS}

This research developed a representative survey applied to 634 workers of public and private health services in the municipality of Camaçari, State of Bahia.

The population was defined as all personnel who provide diverse services and professional care to the population, in hospitals and health units of high, medium and low complexity. The sampling was designed in two stages, to achieve the municipal representation according the level of complexity of the health services and the number of workers and its function. The results, presented in percentages or statistics, can be generalized for the group of health workers in the municipality of Camaçari; and allows estimations of the levels of racial discrimination by the personnel who work in the services, be it hospitals or other less complex health care services.

The size of the sample allows estimating proportions with an estimation error of $5 \%$ or less, based on the supposed maximum variance for proportions $(\mathrm{P}=0.5)$. The sample size must also be sufficient to estimate indicators with scoring scales between 0 and 10 points, with a maximum error of 0.29 points, assuming a uniform distribution, which leads us to an approximate variance of 8.33 .

Two step selection procedures included, as a first step, a selection of health units stratified according to the complexity of the unit; and a second stage to select 656 interviews distributed in hospitals, clinics and health care centers, represented according to their functions (doctors, nurses, dentists, psychologists, social workers, technical, receptionists, security guards, and so on).

The questionnaire included the personal characteristics of the workers' socio-demographic, family, and labor conditions, and their knowledge, perceptions, attitudes and behaviors when asking patients about their racecolor, on racism, inequalities, and affirmative policies. 40 sentences about these issues were extracted from the sentences expressed by individuals interviewed in qualitative studies in Brazil [18, 19]. A Likert scale was used in order to obtain all of the items categorically similar and accurate comparisons within and between your data sets to be tested through a quantitative approach.

The questionnaire was applied to personnel in the health services from September 2015 to February 2016. Data were captured and analyzed using the Statistical Package for the Social Sciences, SPSS.

Correlations between socio-demographic variables and discriminatory sentences were estimated. The Pearson correlation coefficient indicates whether or not there is a linear correlation between selected variables.

Principal Component Analysis - PCA was used to reduce and classify the 40 sentences on racism and discrimination. This reduction would conduce to a lower dimensional set of factors. PCA allows the discovery of a smaller number of components that capture the greatest amount of variance between the 40 original sentences, and the organization of high-dimensional data into more homogenous and reduced sets of sentences. In this research, PCA was used to reduce and organize the sentences into a few dimensions of interest, and to summarize the information from multiple sentences whilst maintaining the diversity among individuals. The sum of answers or sentences made by each individual generates a lineal combination of variables for that individual. These standardized profiles are organized in sets of components [22].

The analysis associates the sentences with the concepts of knowledge, representations, attitudes and practices of the health personnel regarding racism. This simple measure allowed the comparison of multiple dimensions of discrimination, their summarization and classification in groups according to the race-color self-declared by health personnel, and how they believe the patients feel when they are asked about their race-color, in addition to how the personnel perceive racism and affirmative policies.

\section{RESULTS AND DISCUSSION}

\section{Self-declaration of race-color}

In this study we first asked the color-race as an openform question and then we asked it again using the five official categories adopted in the censuses and surveys for one century. As a result, all of the interviewed were able to choose one of the five official options. However, when asked to declare their race-color without reading the five fixed options, only $34 \%$ of them answered spontaneously (32\% of the females and $41 \%$ of males). This percentage is lower than that observed in the total population, and is also lower than that observed among other public employees (Table 1).

Adopting the five official categories provided an almost $100 \%$ response, with very little missing data: $55 \%$ of them self-declared to be brown, around 30\% self-declared to be black, and around $13 \%$ self-declared as white. Less than $2 \%$ declared themselves to be yellow/Asian and less than $1 \%$ indigenous. These proportions are similar for both sexes.

Black is clearly an undesirable category - no men choose this color and only $1 \%$ of women choose it spontaneously. Even in censuses and surveys, this category persisted with very low percentages throughout the 20 th century - between $2 \%$ and $3 \%$ of the population 
self-declared black. In the 21 st century, only after the implementation of affirmative policies, it has increased to no more than 7\%. The larger population groups in Brazil self-declare their race-color as brown.

In this research, all the health employees who spontaneously self-declared themselves as black, work in the public sector, none in private services. The preferred category to substitute the color black is negro, which grammatically means the same color as black. However, in Brazil, according to social movements, negro represents the racial miscegenation and a correspondent social mobility, as well as a sense of cultural attainment [7], while black harks back to the previous situation of slavery, inferiority, and submission.

Table 1 shows the contrast between the results of spontaneity and the closed five official categories of color. The workers who self-declare themselves as white choose the same category when asked for a spontaneous answer or through the five official categories. Those who choose brown among the five official categories can selfdeclare spontaneously as black, brown or negro. Most men and women who choose pardo/brown among the five categories don't respond with their color spontaneously or self-declare themselves as brown, moreno or negro, all of them representing mixed color. In general, few people self-declare as yellow, and they repeat this answer whether in response to an open question or choosing one of the five categories. However, some of them choose white, instead of yellow when asked to choose between the five categories.

Table 1. Percents of Health Personnel according to self-declared race-color, spontaneously versus choosing between five official categories, Camacari, Bahia, Brazil, 2016

\begin{tabular}{|c|c|c|c|c|c|c|c|c|}
\hline \multicolumn{9}{|c|}{ Race-color within the 5 official categories as asked in censuses and surveys } \\
\hline & $\begin{array}{l}\text { Race-color } \\
\text { Spontaneous } \\
\end{array}$ & White & $\begin{array}{l}\text { Black/ } \\
\text { Preto }\end{array}$ & $\begin{array}{l}\text { Brown/ } \\
\text { Pardo }\end{array}$ & $\begin{array}{l}\text { Yellow/ } \\
\text { Asian }\end{array}$ & Indigenous & Total & $\%$ \\
\hline \multirow[t]{10}{*}{ Female } & No answer & 200 & 288 & 749 & 9 & 25 & 1271 & 67.8 \\
\hline & $\%$ of 'no answer' & 15.7 & 22.7 & 53.9 & 1.2 & 1.3 & & \\
\hline & White & 48 & 0 & 0 & 0 & 0 & 48 & 2.6 \\
\hline & Black (Preto) & 0 & 21 & 0 & 0 & 0 & 21 & 1.1 \\
\hline & Pardo (Brown) & 0 & 0 & 178 & 0 & 0 & 178 & 9.5 \\
\hline & Negro (Black+Brown) & 0 & 259 & 83 & 0 & 0 & 342 & 18.2 \\
\hline & Moreno & 0 & 0 & 1 & 0 & 0 & 1 & 0.1 \\
\hline & Yellow (Asian) & 0 & 0 & 0 & 13 & 0 & 13 & 0.7 \\
\hline & Subtotal & 248 & 568 & 1011 & 22 & 25 & 1874 & 100 \\
\hline & Subtotal \% & 13.2 & 30.3 & 53.9 & 1.2 & 0.8 & 100 & 100 \\
\hline \multirow[t]{11}{*}{ Male } & No answer & 63 & 100 & 188 & 9 & 0 & 360 & 58.9 \\
\hline & $\%$ of 'no answer' & 13.9 & 27.3 & 55.6 & 2.3 & 0.8 & & \\
\hline & White & 19 & 0 & 3 & 0 & 0 & 22 & 3.6 \\
\hline & Black (Preto) & 0 & 0 & 0 & 0 & 0 & 0 & 0 \\
\hline & Pardo (Brown) & 0 & 0 & 119 & 0 & 3 & 122 & 20 \\
\hline & Negro (Black+Brown) & 0 & 65 & 20 & 0 & 2 & 87 & 14.2 \\
\hline & Moreno & 0 & 2 & 3 & 0 & 0 & 5 & 0.8 \\
\hline & Mestico (Mixed) & 0 & 0 & 7 & 0 & 0 & 7 & 1.1 \\
\hline & Yellow (Asian) & 3 & 0 & 0 & 5 & 0 & 8 & 1.3 \\
\hline & Subtotal & 85 & 167 & 340 & 14 & 5 & 611 & 100 \\
\hline & Subtotal \% & 13.9 & 27.3 & 55.6 & 2.3 & 0.8 & 100 & 100 \\
\hline \multirow[t]{11}{*}{ Total } & No answer & 263 & 388 & 937 & 18 & 25 & 1631 & 65.6 \\
\hline & $\%$ of 'no answer' & 13.4 & 29.6 & 54.4 & 1.4 & 1.2 & & \\
\hline & White & 67 & 0 & 3 & 0 & 0 & 70 & 2.8 \\
\hline & Black (Preto) & 0 & 21 & 0 & 0 & 0 & 21 & 0.8 \\
\hline & Pardo (Brown) & 0 & 0 & 297 & 0 & 3 & 300 & 12.1 \\
\hline & Negro (Black+Brown) & 0 & 324 & 103 & 0 & 2 & 429 & 17.3 \\
\hline & Moreno & 0 & 2 & 4 & 0 & 0 & 6 & 0.2 \\
\hline & Mestico (Mixed) & 0 & 0 & 7 & 0 & 0 & 7 & 0.3 \\
\hline & Yellow (Asian) & 3 & 0 & 0 & 18 & 0 & 21 & 0.8 \\
\hline & Total & 333 & 735 & 1351 & 36 & 30 & 2485 & 100 \\
\hline & Total $\%$ & 13.4 & 29.6 & 54.4 & 1.4 & 1.2 & 100 & 100 \\
\hline
\end{tabular}

Therefore, it is expected that public employees in health services in Camaçari rarely answer about their color-race via open questions, but all of them answer questions when given the option of five official categories to choose from.

Assigning black as an undesirable category of skin color has to be analyzed in its historical process of construction, and the meanings attributed to the white, black and brown categorizations. The self-declaration of race-color goes far beyond skin color. It has a strong cultural and ideological dimension in terms of social representation [17 ]. Historically, black people have been perceived as a problematic category, negatively affecting intergroup self-perception, 'otherness', and relationships among racialized groups. The origin of racial discrimination against black people is due to more than three centuries of persistent slavery of millions of African and Africa-descendants in Brazil, the trafficking and sale 
of these human beings like animals, the legitimization of their segregation, torture and exploitation of their bodies, and a work force denied their human condition and human rights. This legitimization was reinforced by a pseudoscientific justification - the eugenics that presumed to relate the skin color to inferior moral and intellectual capacities, as well as the natural superiority of white people.

\section{Descriptive results: frequencies}

Descriptive data shows that the large majority of the health personnel - more than $60 \%$, recognize that racism is very frequent in Brazil and they know that it is important to know the health profile and specific health problems of black individuals. However, the majority also believes that it is not necessary to identify race-color in health services, or to provide different treatment by color race, since it would be discriminatory against white individuals.

Moreover, one in three health workers consider that patients would react naturally when answering about their self-reported color, that they wouldn't have any reservations about answering, since that is a normal question in Brazil. However, several negative expectations are also present: one in four workers are concerned that patients would feel bothered, surprised, untruthful, or need clarification (not understanding the question). Around $10 \%$ of them are concerned about patients being irritated or refusing to answer. At the same time, less than $19 \%$ of the workers feel bothered or constrained, as they feel they are being discriminating or offending patients when they ask the question. These proportions are higher among black personnel, compared to white and brown, indicating that these contradictory expectations would be interpreted as some personnel transferring their own fears regarding patients when asking them about their skin color. In an alternative interpretation, $63 \%$ of workers think that it is unnecessary to identify color in health services and around one in three justifies their opinion with several arguments - such questioning could generate controversy, patients don't want to be asked, the community isn't used to it, or it is not part of their job.

Regarding sentences that put this discussion in a technical context, such as it is as natural to ask about color as it is to ask about sex and age, that it is relevant to recognize specific health profiles by race, that blacks have the worst rates of mobility and mortality, and that achieving equality depends on recognizing racial differences, the majority of health workers agree. However, actions to reduce race inequalities are also rejected by the majority of health workers. For example: $62 \%$ of them affirm that offering different treatment by color is discriminating against white people, almost half of them believe that quotas to include black people discriminate against whites, and $40 \%$ affirm that offering a different treatment for black people would crash the health system.

Explicit racism is not so evident, since only four of those interviewed directly assumed that racism does not exist in Brazil, and more than $80 \%$ assume that it exists and is very common. $82 \%$ disagree that black individuals are more aggressive than white individuals and $66 \%$ agree with Brazilian legislation that criminalizes racism, discrimination, and prejudice. However, subtle racism is explicit, since half of them affirm that jokes against black people are normal and part of Brazilian culture.

However, the large majority of workers believe in racial democracy. $61.2 \%$ completely agree and $17.4 \%$ partially agree that there is no need to have a diverse approach in health care to people according to their skin color because the country is interbred - some of them answered the country is interbred and we do not have to fit the person into a single race category or there is no need to classify people by skin color in health care.

Half of the interviewed workers disagree with asking the skin color of patients, and justify this opinion using several excuses. $51.4 \%$ believes that it is not necessary and not part of their job or responsibility, $47 \%$ believes that the community is not accustomed to using these categories, and $50 \%$ does not consider it natural to ask about color as if you were asking the sex or the age of the patient. Others believe that the treatment should be specific for teenagers, women, seniors and black people.

$50 \%$ disagree that it is natural to ask the color/race of the population, just as if asking age or sex: I cannot treat a white or black in the same way, nor a teenager and a senior citizen, nor a man and a woman.

Approximately one in three agrees that it's hard or embarrassing to ask about color, justifying that it could create unnecessary controversy or offend patients.

\section{Correlations}

Religion is positively correlated to the opinion that black individuals are more aggressive than white ones (.122**) and with the knowledge and opinion on the law condemning crimes of racism $(.082 *)$.

Marital status and having children are negatively correlated to several sentences on discrimination, experiences of abuse from patients, and an expectation that patients would feel mistrust when asked about their color.

Having children is negatively correlated to knowledge about illnesses of black people, to the opinion that color/race should be registered in health records, and that patients would feel surprised to be asked about color/race.

Only marital status is positively correlated to the idea that patients would normally answer the question about color/race and negatively correlated to the expectation of surprise when asked this question.

Gender and having children are the variables with the highest correlation coefficients with knowledge of inequalities and discrimination.

Gender is positively related to several attitudes on race inequalities, such as the sentence on divergences in access for whites and blacks as citizens is considered of primary and secondary importance respectively in how victims of violence are received, in the recognition of racially specific diseases to overcome prejudices, and in the understanding that there are worse rates of illness among blacks along with those race inequalities. 
However, gender is negatively correlated to knowledge of sickle cell anemia.

Females are more likely than men to more frequently ask the color of the patient, reading the five options and not completing the form instead of asking the patient, and more likely than men to assume that it is normal to ask color and that it is as natural to ask color as to ask sex or age. Women also are likely to agree that it is important to register color to analyze the racial profile of the population for epidemiological purposes, in the knowledge that the black population has higher rates of mortality and diseases, and to recognize that inclusive attention to health doesn't imply discrimination against whites, and to achieve equality it is important to know these differences. However, women are more pessimistic than men about patients' acceptance to answering the question on their skin color - they likely believe that the patients would question the need or don't understand the question, or refuse to answer. Women are more aware in assuming that racism is very common in Brazil - they have suffered and observed frequent situations of racism and discrimination, and they also suffered more abuse from patients compared to men.

However, women are more resistant to supporting affirmative policies, despite the fact that they are likely to recognize that different treatment and attention standards already exist in health services for citizens considered to be of the $1^{\text {st }}$ and $2^{\text {nd }}$ classes. In spite of women being more likely to perceive injustices, they are likely to agree that it is not necessary to offer different treatments to patients according to their color in health services, and that this kind of affirmative policy means discrimination and racism, and that quotas discriminate against whites. These attitudes reconcile to the idea that just because they are black and disadvantaged we don't have to accept this imposition and with disagreement against the Brazilian legislation that punishes racism.

Men adopt more a pragmatic justification for not asking the patient's color - asking can offend and it isn't part of my job- while women adopt cultural arguments such as it is not necessary to ask, it is not of value to society, or it is complicated to ask color because it generates controversy. Men are also more aware of the social context, and they are likely to relate violence to poverty and the neighborhoods where people live, while women associate violence more directly to racism. Men are likely to agree with explicit racism, like that black people are more violent than white people, and that jokes about black people are normal and a part of Brazilian culture.

It could be interpreted that women are aware of racial inequalities and injustices, but they are also more resistant to correcting these injustices against black people, even adopting a pseudo peacemaking argument, as if not speaking or asking about these injustices keeping quiet - would be the best way to avoid cultural conflicts whereas men assume explicit racism and refer inequality, racism and violence to social context, also considering that that would prevent controversy and conflict.

\section{Principal Component Analysis Model, PCA}

In this research, racism is defined as a multidimensional configuration of beliefs, emotions and behavioral guidelines to discriminate against black individuals, who are considered by whites as members of an out-group.

Applying this concept, and in order to define in-group and out-groups by color, we analyzed the sentences on racism by three groups of health employees - those who self-declare white, black and brown (the majority), those who self-declare yellow/Asiatic or indigenous among the five official categories, and those who, when asked to answer spontaneously, self-declare that they are white. However, they are not so certain that they are white. Therefore, in a descriptive and statistics approach, they were included in the group of self-declared brown, who culturally act as self-declared white. Moreover, the few interviewed who didn't answer the question on their color were included in the more numerous and mixed group as brown people. This classification has the objective to compare explicit and subtle racism, considering in-groups and out-groups of white, black and brown individuals.

The questionnaire applied in the field included 40 questions about racism - how the health personnel ask and feel when they are completing forms and question patients on their race-color, and the knowledge, perceptions, attitudes and behaviors of the personnel on racism. The questions on racism were extracted from previous qualitative studies in Brazil.

The method of Principal Components Analysis - PCA was applied in order to reduce a high set of 40 sentences representing multidimensional concepts like knowledge, perceptions, attitudes and behaviors, related to otherness, values and ideology regarding racism. Each set of sentences is organized according to their meanings, related to the concepts of knowledge, perceptions, attitudes and behaviors, otherness', values and ideology.

The KMO value is higher than 0.7 in the three groups white, black, and brown - and the Bartlett's Test of Sphericity is significant - equal to zero (Table 2), indicating that PCA is an adequate method to reduce data in this case. After eliminating the variables with very low correlations, the KMO increased to over 0.7 and the Bartlett's test is significant for the three groups - white, black, and brown. For white and black individuals, six principal components explain more than $50 \%$ of variance, and for brown individuals eight components are necessary.

Reducing the number of variables from 40 sentences on racism provides a summarized set of new variables, named principal components. The new model explains most of the variance from the original set of several variables.

The Table of Commonalities represents the percentage of variance explained by each variable; it is useful to eliminate the variables with very low correlation values and to indicate the most important factors (higher than 0.7) when explaining the variance in each group (Table 3). 
Table 2 : KMO and Bartlett's Test for Sentences on Racism among Health Personnel in Camacari, Bahia, Brazil, 2016.

KMO and Bartlett's Test

\begin{tabular}{|c|c|c|c|c|}
\hline & & WHITE & BLACK & BROWN \\
\hline $\begin{array}{l}\text { Kaiser-Meyer-Olkin Measure } \\
\text { Sampling Adequacy }\end{array}$ & & 0.656 & 0.799 & 0.701 \\
\hline Bartlett's Test of Sphericity & $\begin{array}{l}\text { Approx. Chi-Square } \\
\text { Df } \\
\text { Sig. }\end{array}$ & $\begin{array}{l}14999.972 \\
946 \\
0\end{array}$ & $\begin{array}{l}22613.422 \\
946 \\
0\end{array}$ & $\begin{array}{l}17660.945 \\
946 \\
0\end{array}$ \\
\hline
\end{tabular}

Source: own estimations from primary database on racism in health services in Camacari.

Table 3. Total Variance for Sentences on Racism, explained in the Rotation Sums of Squared Loadings, by Selfdeclared Color of Health Personnel in Camacari, Bahia, Brazil, 2016.

\begin{tabular}{|c|c|c|c|c|c|c|c|c|c|c|c|c|c|c|c|c|c|c|}
\hline \multirow[b]{4}{*}{$\begin{array}{l}\vec{\Xi} \\
\vec{\Xi} \\
\stackrel{\Xi}{\Xi} \\
\dot{\Xi}\end{array}$} & \multicolumn{18}{|c|}{ Total Variance Explained } \\
\hline & \multicolumn{6}{|c|}{ WHITE } & \multicolumn{6}{|c|}{ BLACK } & \multicolumn{6}{|c|}{ BROWN } \\
\hline & \multicolumn{3}{|c|}{ Initial Eigenvalues } & \multicolumn{3}{|c|}{$\begin{array}{l}\text { Rotation Sums of } \\
\text { Squared Loadings }\end{array}$} & \multicolumn{3}{|c|}{ Initial Eigenvalues } & \multicolumn{3}{|c|}{$\begin{array}{l}\text { Rotation Sums of } \\
\text { Squared Loadings }\end{array}$} & \multicolumn{3}{|c|}{ Initial Eigenvalues } & \multicolumn{3}{|c|}{$\begin{array}{l}\text { Rotation Sums of } \\
\text { Squared Loadings }\end{array}$} \\
\hline & $\begin{array}{c}\bar{\pi} \\
0 \\
\end{array}$ & 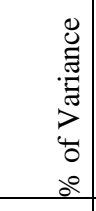 & 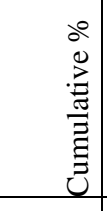 & 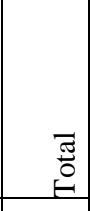 & 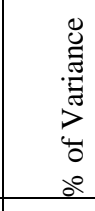 & 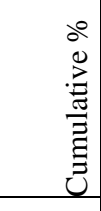 & 胥 & 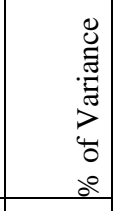 & $\begin{array}{c}0 \\
0 \\
\stackrel{\Xi}{\Xi} \\
\Xi \\
\Xi \\
\Xi \\
\Xi\end{array}$ & 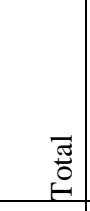 & 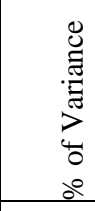 & 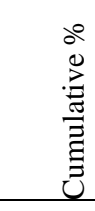 & ثี & 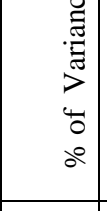 & 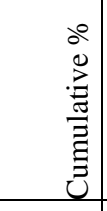 & 胥 & 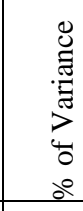 & 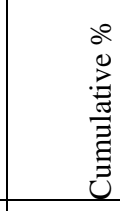 \\
\hline 1 & 9.2 & 21.0 & 21.0 & 8.1 & 18.5 & 18.5 & 9.8 & 22.3 & 22.3 & 9.1 & 20.7 & 20.7 & 5.1 & 11.6 & 11.6 & 2.8 & 6.5 & 6.5 \\
\hline 2 & 3.7 & 8.3 & 29.3 & 3.7 & 8.5 & 27.0 & 4.2 & 9.5 & 31.7 & 3.0 & 6.9 & 27.6 & 4.0 & 9.0 & 20.6 & 2.8 & 6.3 & 12.8 \\
\hline 3 & 3.2 & 7.2 & 36.5 & 2.6 & 5.9 & 32.9 & 2.8 & 6.3 & 38.0 & 2.7 & 6.1 & 33.7 & 2.4 & 5.5 & 26.1 & 2.6 & 6.0 & 18.7 \\
\hline 4 & 2.9 & 6.6 & 43.0 & 2.5 & 5.7 & 38.5 & 2.5 & 5.7 & 43.7 & 2.4 & 5.3 & 39.0 & 2.3 & 5.3 & 31.3 & 2.4 & 5.5 & 24.2 \\
\hline 5 & 2.3 & 5.3 & 48.4 & 2.3 & 5.3 & 43.8 & 2.1 & 4.7 & 48.4 & 2.3 & 5.3 & 44.4 & 1.8 & 4.1 & 35.5 & 2.0 & 4.6 & 28.8 \\
\hline 6 & 2.1 & 4.7 & 53.0 & 2.3 & 5.2 & 49.0 & 1.7 & 3.9 & 52.3 & 2.1 & 4.8 & 49.1 & 1.8 & 4.0 & 39.5 & 2.0 & 4.5 & 33.3 \\
\hline 7 & 1.8 & 4.1 & 57.2 & 2.0 & 4.4 & 53.5 & 1.6 & 3.7 & 56.0 & 1.9 & 4.4 & 53.5 & 1.6 & 3.7 & 43.2 & 1.9 & 4.4 & 37.7 \\
\hline 8 & 1.6 & 3.7 & 60.9 & 1.8 & 4.2 & 57.7 & 1.6 & 3.6 & 59.5 & 1.8 & 4.0 & 57.5 & 1.5 & 3.4 & 46.6 & 1.9 & 4.3 & 42.0 \\
\hline 9 & 1.4 & 3.3 & 64.2 & 1.8 & 4.0 & 61.7 & 1.5 & 3.4 & 62.9 & 1.6 & 3.6 & 61.1 & 1.3 & 2.9 & 49.5 & 1.8 & 4.1 & 46.1 \\
\hline 10 & 1.3 & 2.9 & 67.1 & 1.5 & 3.4 & 65.0 & 1.2 & 2.7 & 65.6 & 1.5 & 3.4 & 64.6 & 1.3 & 2.9 & 52.4 & 1.6 & 3.5 & 49.7 \\
\hline
\end{tabular}

The dimensionality reduction by PCA is used to analyze results from a visualization of the patterns from the racism sentences that operate together. These patterns represents the sharing of social attitudes, beliefs and expressions of negative feelings, or the manifestation of hostile or discriminatory behavior against members of other groups, as defined by [13] in his concept of prejudices.

Each component show the major contributors (the higher positive values) that explain the trends, or the common perspective of the individuals who self-declare as white, black or brown. Therefore, the set of components summarize articulated patterns of beliefs, emotions, evaluations and behavioral orientations about the 'other' - for example, in the out-group of blacks, being different from the in-group of whites, and vice-versa. Moreover, this concept applied principal components allowing the observation of different combinations among groups, since racism is not always present in a single configuration, but in various configurations, being more appropriate then to talk about racism than racism [14].

As race and ethnicity are social constructions used to identify, categorize and label groups of people, racism is analyzed in terms of in-group and out-group in this multivariate analysis [13].

\section{Rotation Matrix of Components}

For white personnel, in the first component, the main variables grouped are related to resistance to asking the patient's color-race - It shouldn't be asked, it is not my job (0.951), despite knowing that inequalities exist There are worst rates for blacks, it is relevant to focus on inequalities (0.95) and that it is Relevant to recognize specific health problems of blacks and race inequalities (0.685), that there are clearly perceptions about social injustice. However, they disagree with policies to correct these social inequalities adopting the reverse racism argument - Different treatment by color race is discriminatory against white individuals (0.948), and 
justify their opinions with explicit racism -Black people are more violent than white people $(0.81)$. Therefore, in the first place, the perceptions of white personnel about racism are mainly oriented to recognize racial inequalities and to justify the better position of their in-group in contrast to the worse position of the out-group - black people - who they perceive as violent by nature. There are no ambiguities, but a clear perception of the preference to maintain the status quo of inequalities in favor of their in-group, while being conscious and aware about inequalities and the associated risks in order to maintain their own social position.

In the second component, white personnel completely agree that Racism exists in Brazil and that it is very common. In the third component, they believe that asking about color can offend patients and, in the fourth component, they are afraid to discriminate between patients by asking their color, as they already know the more common diseases of the black population. This combination of sentences indicates the recognition of structural racism in Brazilian society and the care taken to not allow it to generate conflict in the intergroup relationships.

In the fifth component white personnel adopt a social approach and recognize that violence could be related to poverty and the place where people live, relating racism to a social inequality perspective.

In the sixth component white personnel assume that, in spite of the fear of offending or discriminating, they used to ask patient's color, but sometimes they answer the question themselves without asking the patient. This sentence confirms that not offending and discriminating is not necessarily orientated to a sense of compassion or otherness, but likely to the belief of their better intellectual ability to define the race-color of the members of the out-groups.

White personnel put their technical knowledge in first position to build a dialogue that recognizes racial and social inequalities, while they refuse any attempts to correct injustices - affirmative policies - since they believe that their in-group - whites - would be discriminated against, meaning the loss of the superior position they have in the status quo. At the same time, they openly express explicit racism as ideology, classifying blacks as more violent by nature, and they act in accordance with it when they classify members of outgroups by themselves, without asking patient as established rules demand.

Black personnel are conscious and aware of structural racism. In the first component they strongly identify that racism exists in Brazil and it is very common (0.92). However, they believe that it is unnecessary to ask the color of patients in health services (0.87), while, contradictorily, they assume that it is still relevant to recognize inequalities and the specific health problems among the black population (.81). How do black personnel think that data on inequalities would be produced, if not by asking patients? There is a clear contradiction between their technical knowledge and beliefs. Moreover, black personnel disagree with affirmative policies and, like whites, they use reverse racism as argument: quotas discriminate against white people (0.80). These ambiguities show the unconsciousness of black's population disadvantages in the intergroup relationships and play against their own concrete interests. Therefore, these beliefs are mainly oriented by ideology.

The second component includes a social approach to explain violence, related to poverty, behavior (what they wear), racism and the place where they live (slums).

In the third component, black personnel, when asking about the color of patients, feel that they could offend or be misunderstood, and finally they reaffirm that it is unnecessary to ask.

In the fourth component, their practices are according to procedures - they read the options of colors to the patient and, in general, they don't respond on behalf of the patients, although they believe that patients would feel constrained if asked about their color.

In brief, black personnel are more aware of racism, but they also reproduce subtle racism through contradictory sentences that consider it offensive to ask color and, worse than that, they believe that affirmative policies like quotas to guarantee equality and black rights operate against whites. They reproduce the same sentences of their out-group (white people), except in a different order - they put structural racism in the first position. Moreover, they don't tend to answer the color question on behalf of patients.

For black individuals, perceiving structural racism in society is not enough to orient their perception of inequalities and injustices, and to position them in favor of acting to correct these injustices and discrimination against blacks, with concrete actions. This result can be interpreted in the context of incongruities between the beliefs and values, and between the latter and practices.

These contradictions in inter-groups identity, belonging, and relationships should be explained in the field of ideological positions. Although it is more surprising to find this among black personnel, it is more evident among the personnel who self-declare as brown, or miscigenated, as will be analyzed in the next session.

Brown personnel have lower level of coefficients (maximum 0.7), compared to white and black groups (maximum 0.9). In the first component they feel unsettled or fear they could offend patients when asking their color, and they put violence in a social perspective, associated to living in slums. In the second component they believe that it is unnecessary to ask patients their color, justifying this point of view culturally, like the community isn't used to doing it, transferring their own fears to the collective. And in the third component they adopt a practical or pragmatic position against asking the color of the patients: It shouldn't be asked, it is not my job. All the most important sentences in the $1^{\text {st }}, 2^{\text {nd }}$ and $3^{\text {rd }}$ components are related to subtle racism, and evading the responsibility of registering the color to make racial inequalities evident, always referring to the patients as the problem, transferring their own prejudices to the other, and hiding their subtle racism behind a narrative of supposed compassion and tolerance like I don't want to 
offend, the community isn't used to it, and violence is social (not racial).

In the fourth component, brown personnel assume explicit racism in their narrative, and the main variables are - jokes against black people are normal and part of Brazilian culture, and quotas discriminate against whites. Racist jokes are seen as normal culture and, in fact, it includes a subtle perception that blacks are violent, stupid, or inferior by nature, as is represented in these jokes.

In the fifth component they adopt the technical argument and assume that race inequalities exist and should be measured. Asking color-race is as natural as asking age/sex, and to provide different treatment and to achieve equality, it is necessary to recognize racial differences.

\section{CONCLUSIONS}

Although Brazilians know that racism is criminalized in their country, explicit racism is still present in the most numerous groups - brown and white personnel. The sentence that black people are more aggressive than whites is less frequent (almost 15\%), but the perception that jokes humiliating blacks aren't racism, but just part of the Brazilian culture is one of the sentences that almost half the personnel interviewed agree with. Both sentences are highly correlated, and they are included among the main components of racist sentences of white and brown personnel, and the latter is closely identified with the white in-group, instead of the black personnel.

The perception of black aggressiveness is highly correlated to the religion of the respondents, while

\section{ACKNOWLEDGMENTS}

This research was financed by the National Council of Scientific and Technological Development - CNPq and the Ministry of Health of Brazil and received the support from the Health Secretary of Camacari, Bahia, Brazil.

\section{REFERENCES}

[1] Fernandes, F., 1965. The Integration of Black in Class Society. São Paulo: Dominus S.A

[2] Ribeiro, D. A., 2012. Ubuntu: Human Rights and the Health of the Black Population. In: L. E. Batista, J. Werneck, \& F. Lopes (Org.), Health of the Black Population (2nd ed., pp. 122-145). Rio de Janeiro: Brazilian Association of Black Researchers. (Black and Black Collection: Research and Debates)

http://bvsms.saude.gov.br/bvs/publicacoes/saude_p opulacao_negra.pdf

[3] Klein, H. S.; III, Ben Vinson, 2007. African Slavery in Latin America and the Caribbean (2nd ed.). New York: Columbia University.

[4] Roediger, D., 2000. Towards the Abolition of Whiteness. London: Verso.

[5] Alencar, J. A., 2013. Stay Where You Belong: Review of Machado de Assis-Multiracial Identity acceptance of humiliating jokes is significantly correlated to the skin color self-declared by the worker.

The myth of racial democracy is not as important in descriptive and correlation analysis as explicit racism, and some of these sentences comprise the groups of variables related as an indicator of racism.

The large preference by all three groups to the sentence 'it is not necessary to identify people according to color in health services is clearly inspired by the myth of racial democracy and equalitarian values (the country is mixed), as presumed in the hypothesis that everyone is equal according to law. These are two typical masked and defensive sentences, which are in contradiction to several other sentences on explicit racism (blacks are violent and jokes against blacks are legitimate culture), and subtle racism, like avoiding asking the color to prevent conflicts, controversy, inconvenience and problems, and, finally, rejecting affirmative policies in practices.

Despite the large majority of workers recognizing that racism exists in Brazil, their narratives indicate the predominance of a modern or subtle type of racism, based more on social prejudices than on rational recognition and indignation against inequalities - even among black and brown personnel. These results reconcile with [14] findings in Portugal, showing that the ambiguities in racism perception are oriented by ideology, and can be related to the ambiguity among the main values in modern society, such as universalism and equality, against meritocracy and individual success.

The research was carried out with a representative survey among health service personnel of in the municipality of Camaçari, in Bahia State, Brazil, as an evaluation of the National Policy for the Integral Health of the Black Population, approved in 2009.

and the Brazilian Novelist, by G. Reginald Daniel. Machado de Assis on line, v. 6, n. 11, pp. 134-139, June 2013. Rio de Janeiro: Foundation Casa de Rui Barbosa. DOI: 10.1590/S1983$\underline{68212013000100010}$

[6] Amaral, S. P., 2011. The History of the Negro in Brazil. Training Course for the Teaching of History and Afro-Brazilian. Brasilia: Ministry of Education. Secretary of Continuing Education, Literacy and Diversity; Salvador: East Africa Studies Center. http://machadodeassis.net/download/numero11/arti go09.pdf

[7] Brasil, Ministry of Health 2013. National Comprehensive Health of the Black Population Policy on Health Unique System (SUS) Policy (2nd ed.). Brasília: Ministry of Health. http://bvsms.saude.gov.br/bvs/publicacoes/ politica nacional saude integral populacao.pdf 
[8] Brasil, 2016 SEPPIR. Promoting Racial Equality. For a Brazil without Racism. 1st Edition. Brasilia, 2016. Special Secretariat for the Promotion of Racial Equality (SEPPIR). Ministry of Women, Racial Equality, Youth and Human Rights. Org. Katia Regina da Costa Santos \& Edileuza Penha de Souza.

[9] Carvalho, J. M., 2004. The Bestialized-Rio de Janeiro and the Republic It Was Not. São Paulo: Compania Das Letras.

[10] Santos, M. A., 2007. Moreninho, Neguinho, Pretinho (Little Brown, Little Negro, Little Black). Brasilia: Ministry of Education.

[11] Batista, L. E., Monteiro, R. B., \& Medeiros, A. R., 2013. Racial and Health Inequities: The Cycle of Health Policy of the Black Population. Health Debate, Rio de Janeiro, 37, pp. 571579. http://goo.gl/HSXwrz

[12] Diwan, P., 2015. Pure Race, a History of Eugenics in Brazil and in the World. Editora Contexto. Sao Paulo.

[13] Brown, R., 1995. Prejudice: its Social Psychology. Oxford: Blackwell Publishers.

[14] Vala J., Brito R. and Lopes D., 1999. Expressões dos Racismos em Portugal. Imprensa de Ciencias Sociais. Lisbon.

[15] Sherif, M., Sherif C., 1988. Groups in Harmony and Tension: an Integration of Studies on Intergroup Relations. New Iork. Harper and Row.

[16] Silva Filho, P., 2008. Affirmative Action Policies in Brazilian Education: A Case Study of Vacancies Reserve Program for Entry into the Federal University of Bahia. Doctoral Thesis, Salvador: UFBA.
[17] Osório, R. G., 2003. The Classification System of Color or Race at IBGE. Discussion Paper 996, Brasilia:IPEA. http://www.ipea.gov.br/portal/index. php?option $=$ com_content $\&$ view $=$ article $\&$ id $=4212$

[18] [ 18 ] Santos, J. E., \& Santos, G. C. S., 2013. Narratives of Primary Care Professionals on the National Comprehensive Health Policy for the Black Population. Health Care Debate, 37, 571579. http://goo.gl/HSXwrz

[19] Dias, J., Giovanetti, M. R., \& Santos, N. J. S., 2009. Asking Offends: What Is Your Color or Race/ Ethnicity?: Answering Helps Prevention. In: Prevention of STD/AIDS. CRTDST/AIDS. http://www3.crt.saude.sp.gov.br/arquiv os/arquivos_biblioteca_crt/livro_quesito_cor.pdf

[20] Araújo, C. L. F.,et al. 2010. The Question of Color/Race in Health Forms: The Vision of Health Professionals. Revista Enfermagem UERJ, 18, 241246. http://www.facenf.uerj.br/v18n2/v18n2a13.pdf

[21] Goes, E. F., \& Nascimento, E. R., 2013. Black and White Women and Levels of Access to Pre-ventive Health Services: An Analysis of Inequalities. Saúde em Debate, 37, 571-579. DOI: 10.1590/S010311042013000400004

[22] Wold S., Esbensen K., Geladi,, 1987. P. Principal component analysis. In Chemometrics and Intelligent Laboratory Systems. Volume 2, Issues 1-3, August 1987, Pages 3752. DOI: $10.1016 / 0169-7439(87) 80084-9$

[23] Grandi, J., Days, M. T. G., \& Glimm, S., (2013) Perceptions of Those Who Ask-What's Your Color? Rio de Janeiro, 37, 588-596. DOI: 10.1590/S0103-11042013000400006 